\title{
O GLOBO REPÓRTER NO TWITTER: O DISCURSO COLETIVO DOS TELESPECTADORES
}

\author{
The Globo Reporter on Twitter: the collective speech of telespectors
}

El Globo Repórter en Twitter: enunciaciones colectivas de espectadores

\section{Bianca Pereira da Silva $^{* 1}$, Carlos Golembiewski ${ }^{2}$}

${ }^{1}$ Graduanda no Curso de Comunicação Social Jornalismo, Universidade do Vale do Itajaí,

Centro de Educação de Ciências Humanas e da Comunicação, Itajaí - SC, Brasil.

${ }^{2}$ Docente no Curso de Comunicação Social Jornalismo, Universidade do Vale do Itajaí, Centro de Educação de Ciências Humanas e da Comunicação, Itajaí - SC, Brasil.

*Correspondência: Universidade do Vale do Itajaí, Centro de Educação de Ciências Humanas e da Comunicação, Curso de Comunicação Social Jornalismo. Rua Uruguai, 458 - Centro, CEP: 88302202 - Itajaí, SC - Brasil Caixa-postal: 360.e-mail carlosinterligado@yahoo.com.br

\section{RESUMO}

Este estudo tem por objetivo revelar os comentários do Twitter feitos pelos telespectadores do Globo Repórter durante a exibição do programa. Entre os objetivos específicos estão: um perfil do programa e uma análise histórica do surgimento das redes sociais. A escolha do Globo Repórter se deu porque ele é um dos programas que está há mais tempo no ar na TV brasileira. Para isso, utilizou-se como referencial teórico: Globo Repórter (Andrade, 2002); (Souza, 2004), (Rezende, 2000); Rede Social na Internet (Recuero, 2009), (Body \& Ellison, 2007) e Twitter (Santaella e Lemos, 2009), (Zago,2014). Como método para desenvolver esse estudo, usou-se a técnica do Discurso do Sujeito Coletivo proposta por Lefévre\&Lefévre (2003). Para desenvolver a técnica, foram analisadas duas edições do Globo Repórter e coletados os comentários dos telespectadores por meio da hashtag \#GloboReporter, durante a exibição do programa. Entre as conclusões, pode-se dizer que ao assistir o Globo Repórter, a população relaciona a sua realidade com aquilo que é exibido no programa.

Palavras-chaves: Globo Repórter. Twitter. Discurso do Sujeito Coletivo

\section{ABSTRACT}

This study aims to reveal the comments of Twitter made by Globo Reporter viewers during the program's exhibition. Among the specific objectives are: a profile of the program and a historical analysis of the emergence of social networks. The choice of Globo Reporter was because it is one of the programs that has been in the air for the longest time on Brazilian TV. For that, it was used as theoretical reference: Globo Repórter (Andrade, 2002); (Souza, 2004), (Rezende, 2000); Social Network on the Internet (Recuero, 2009), (Body \& Ellison, 2007) and Twitter (Santaella and Lemos, 2009), (Zago, 2014). As a method to develop this study, was used the Collective Subject Discourse technique proposed by Lefevre \& Lefévre (2003). To develop the technique, two editions of the Globo Reporter were analyzed and the viewers' comments were collected through the hashtag \#GloboReporter, during the program's display. Among the conclusions, it can be said that when watching the Globo Reporter, the population relates its reality to what is displayed in the program.

Keywords: Globo Reporter. Twitter. Collective Subject Discouse;

\section{RESUMEN}

Este estudio pretende mostrar los comentarios hechos por los espectadores en Twitter del Globo Repórter durante la visualización del programa. Los objetivos específicos son: el perfil del programa y un análisis histórico de la aparición de las redes sociales. La elección del Globo Reporter era porque él es uno de los programas más antíguos en el aire en la televisión brasileña. Para esto, se utilizó como marco teórico: Globo Reporter (Andrade, 2002); (Souza, 2004) (Rezende, 2000); Las redes sociales en Internet (Recuero, 2009), (Body \& Ellison, 2007) y Twitter (Santaella y Lemos, 2009), (Zago, 2014). Como método para desarrollar este estudio, se utilizó la técnica del Discurso del Sujeto Colectivo propuesto por Lefèvre y Lefèvre (2003). Para desarrollar la técnica, se analizaron dos ediciones del Globo Reporter y recoger los comentarios de los espectadores a través de 


\section{INTRODUÇÃO}

As mídias sociais se tornaram uma porta de entrada para que o público se aproxime com mais frequência dos programas de TV. Elas têm se tornado um meio para essa interação direta do telespectador com os telejornais, reality shows, novelas e programas de entretenimento. Segundo dados oficiais do IBOPE (2015), 67\% da população brasileira está conectada à internet em busca de informações e entretenimento. E, $18 \%$ assistem TV enquanto navega na internet.

Esse crescimento das redes sociais utilizando a programação da televisão como pauta, ganhou destaque principalmente no Twitter. O microblog registra atualmente 320 milhões de usuários em todo o mundo. Desse total, $98 \%$ assiste TV todos os dias, enquanto um em cada quatro usuários procura por informação sobre o que assiste e um em cada cinco divide suas opiniões sobre um programa de TV. Apesar do número expressivo da ferramenta, Recuero (2015) avalia em uma entrevista disponibilizada pelo Click RBS que o Twitter não está crescendo, mas têm apostado nas narrações em tempo real dos acontecimentos. "O papel fundamental da rede continua sendo o informativo. É esse caráter que o mantém o vivo. $\mathrm{O}$ microblog tem a força da narração em tempo real, uma aposta que a própria rede ressaltou ao mudar o questionamento central de "o que você está fazendo?" para "o que está acontecendo?".

Por conta dessa apropriação da ferramenta com os meios televisivos, vários programas passaram a se adequar e adotar redes sociais para a interação ativa com o público. É o caso do Globo Repórter, exibido às sextas-feiras, na Rede Globo desde 1973. Há 43 anos no ar, o programa teve que se adequar às novas tecnologias e hoje possui uma página no Facebook com quase 5 milhões de curtidas e mantém um perfil no Twitter com 520 mil seguidores. Em seu perfil no Twitter é notória a presença dos seguidores comentando os temas do programa e fazendo críticas. Por outro lado, esse perfil só interage com o internauta revelando as pautas abordadas pelo programa em sua própria timeline. Pela importância do Twitter para o programa, este trabalho de pesquisa investiga a seguinte questão: o que o telespectador do Globo Repórter comenta no Twitter durante a exibição do programa?

Visto que essa interação do telespectador/internauta com programas de TV tem se tornado frequente, esse artigo tem como objetivo geral, analisar os comentários do Twitter feitos pelos telespectadores do Globo Repórter durante a exibição do programa. Sendo assim, os objetivos específicos são: fazer um perfil do programa Globo Repórter; elaborar uma análise histórica das redes sociais, principalmente o Twitter; e, verificar se os comentários enviados pelo Twitter fazem críticas ou elogios ao programa.

Apontado como um dos maiores sucessos da TV Globo até hoje, o programa carrega temáticas culturais, do cotidiano, de saúde, economia, educação, ciência e política. Por conta da sua temática variada, o Globo Repórter registra desde de sua estreia uma audiência consideravelmente alta. Priolli (1985, p. 33) afirma que a emissora atingiu "Uma participação de $70 \%$ no mercado nacional de TV" e com isso, tornou o Globo Repórter um programa tão prestigiado pelos brasileiros. Atualmente, o programa registra picos de 22 pontos de audiência, equivalentes a 41 milhões de 
telespectadores como foi registrado em 22 de fevereiro de 2016 pelo IBOPE (2016), após a estreia da nova temporada do programa.

Com a crescente utilização das mídias sociais o programa precisou se modernizar, acompanhando os avanços da sociedade e da própria emissora. Dessa forma, criou perfis em Sites de Redes Sociais para se aproximar do público, como o Facebook e o Twitter. Para se adequar ao público dos Sites de Redes Sociais, em especial do Twitter, o programa faz postagens diariamente com vídeos convidando os internautas a assistir ao próximo programa, além de fotos e gifs dos lugares visitados. Esta interação com o público do Twitter faz com que a rede social participe ativamente com comentários, sugestões e críticas para o programa. Durante a sua exibição, a hashtag \#globoreporter facilita a participação do internauta.

O Twitter teve seu pico de crescimento em 2010 no Brasil, mas perdeu usuários à medida que o site deixou de ser só conversação. Recuero (2015) explica: "No início, o Twitter tinha a característica da instantaneidade aliada à conversação. Com o surgimento de novas plataformas, como Facebook, Snapchat e WhatsApp, os usuários acabaram migrando o bate-papo para elas". Atualmente, o Twitter utiliza como estratégia para voltar a crescer as integrações com programas de televisão. Segundo informações divulgadas pela empresa (TWITTER, 2015), a estratégia de crescimento da plataforma está vinculada com as integrações que realiza com programas de TV no país em diferentes áreas: reality shows, telejornais, programas esportivos e novelas. Santaella e Lemos (2010, p.26) explicam que o sucesso do Twitter "encontra-se na potência da era da mobilidade para a comunicação on-line, em tempo real". Por viver de fato essa mudança de paradigma, onde agora o telespectador pode falar, o tema deve ser abordado pela área de Comunicação Social.

\section{REFERENCIAL TEÓRICO}

Para realizar esse estudo, buscou-se referências sobre o surgimento do Globo Repórter por Andrade (2002), Souza (2004) e Rezende (2000). Precisou-se também, identificar o conceito de Rede Social na Internet por Recuero (2009) e Boyd \& Ellison (2007) e o Twitter por Zago (2014), e Santaella e Renata Lemos (2009) para melhor entender a análise da pesquisa.

\section{Globo Repórter}

O Globo Repórter, objeto principal desse estudo, estreou em 03 de abril de 1973 exibido semanalmente as sextas-feiras, às $23 \mathrm{~h}$. No começo, os assuntos abordados no programa tinham temas bem diversos divididos em categorias de política, viagem e cultura. No site do programa (GLOBO REPÓRTER, 2016) tem um breve resumo que explica: "no começo, o Globo Repórter se destinava a analisar com mais profundidade os principais acontecimentos jornalísticos nacionais e internacionais do mês, que, por uma questão de tempo, não podiam ser detalhados nos telejornais". Estes acontecimentos eram retratados de forma documental, assim como o programa Globo Shell de 1971, através de cineastas que se renderam a televisão: "Eu mesmo tive que defender minha ida para a TV em diversas ocasiões, rebatendo a sistemática acusação de que isso era uma 'traição' ao cinema, à cultura e à oposição", conta Andrade (2002, p. 39).

Verificou-se uma profícua ligação entre TV e cinema pela ação de cineastas que não viam o porquê de barreiras tão grandes entre as duas áreas profissionais. Ligação que se 
aprofundaria, logo em seguida ao desmantelamento da Hora da Notícia, em 1974, no setor de reportagens especiais da TV Globo/SP, em programas como Domingo Gente, Esporte Espetacular, Fantástico e, principalmente, o Globo Repórter, este último estruturado pelo cineasta Paulo Gil Soares (TV Globo/Rio) como um encontro entre cineastas (documentaristas) e TV, em continuidade à experiência do programa Globo/Shell, também de cineastasdocumentaristas (BATISTA DE ANDRADE, p. 66).

As primeiras filmagens do programa eram feitas em películas de $16 \mathrm{~mm}$ com o som vindo direto da câmera. Não havia repórter, apenas uma narração do atual apresentador Sérgio Chapelin. No site globo.com/globoreporter (2016) é possível encontrar uma parte da história em que diz: "vários programas estrangeiros e muitas imagens de arquivo eram utilizados nos primeiros anos do Globo Repórter. As edições se dividiam em três ou quatro temas, com exceção do Globo Shell Especial”.

O formato de documentário durou mais uma década no programa passando por assuntos de importância histórica, sociais, políticas, científicas e tecnológicas. Souza (2004, p. 145) salienta que "a seriedade do gênero permaneceu a fim de levar ao telespectador uma visão do mundo, da realidade de outros países e de outras culturas". Ele ainda completa:

[...] A proposta de todo documentário é buscar o máximo de informações sobre um tema. Por isso, sua duração é maior do que as reportagens apresentadas pelos telejornais. As produtoras internacionais de documentários realizam filmes com duração média de trinta e cinquenta minutos. No Brasil, os programas do gênero inicialmente tinham em média trinta minutos, como o Globo Repórter (Globo) ou SBT Repórter (SBT). Mas houve significativa redução, o que desvirtua o caráter de documentário, merecendo apenas o crédito de grande reportagem. (ARONCHI DE SOUZA, 2004, p. 146).
Em 1983, o Globo Repórter passou por uma de suas maiores transformações. Do gênero documentário filmado por película, o programa começou a se aproximar mais do formato reportagem e apresentado em videotape. Rezende (2007, p.12) explica que para se adaptar ao novo formato, foi necessário contratar repórteres especiais da própria emissora, colocando presente a figura do repórter no vídeo. Em 1985, as edições do programa focavam apenas em um único tema, dividido em cinco blocos que somavam 45 minutos, exibido apenas nas sextasfeiras. Essas transformações permanecem até hoje.

Quanto à audiência do programa, Priolli (1985, p. 33) afirma que a emissora atingiu "uma participação de 70\% no mercado nacional de TV" e com isso tornou o Globo Repórter um programa tão prestigiado pelos brasileiros desde sua estreia. Atualmente, o programa registra picos de 22 pontos de audiência segundo dados oficiais do IBOPE, o que equivale a 41 milhões de telespectadores. Com o avanço da tecnologia, o programa precisou se adequar aos moldes da sociedade e da própria emissora, então criou sites de redes sociais para se aproximar do público. No Facebook, a página oficial pode ser encontrada no endereço facebook.com/globoreporter e contém 4.692.723 curtidas. Enquanto o Twitter, encontrado em twitter.com/globoreporter tem $520 \mathrm{mil}$ seguidores. Esses números foram contabilizados para essa pesquisa em 11 de abril de 2016. Todo esse público registrado nas redes sociais interage ativamente com comentários, sugestões e críticas para o programa.

\section{Redes Sociais na Internet}


Para explicar o sentido de rede social conhecido popularmente e a forma como o ser humano interage por meio dela. Recuero (2009, p.13) explica as redes sociais na internet como agrupamentos complexos instituídos por interações sociais apoiadas em tecnologias digitais de comunicação. Para ela, essa comunicação, mais do que permitir aos indivíduos comunicar-se, amplificou a capacidade de conexão, permitindo que redes fossem criadas e expressas nesses espaços.

Para entender com mais clareza como uma rede social é definida, busca-se o conceito de Wasserman e Faust (1994) e Degeme e Forse (1999) citados por Recuero (2009): uma rede social é definida como um conjunto de dois elementos: atores (pessoas, instituições ou grupos; os nós da rede) e suas conexões (interações ou laços sociais). É através dessas redes que é possível observar as interações e conexões estabelecidas entre diferentes atores.

Um estudo realizado por Reid (1991) sobre o Internet Relay Chat (IRC) e traduzido pela autora revela que um sistema de bate-papo com mensagens privadas teve a seguinte descoberta: a interação social no ciberespaço pode se dar de duas formas: síncrona e assíncrona. A primeira simula a interação em tempo real como uma resposta quase que imediata. Já a segunda requer um tempo maior de espera para o agente responder à mensagem. Primo $(1998$, p.7) cita outras duas formas de interação: a interação mútua caracterizada por relações interdependentes, em que cada integrante participa da construção inventiva e cooperada da relação, afetando-se mutuamente; e a interação reativa que é limitada por relações determinísticas de estímulo e resposta. Partindo deste princípio, observa-se que a interação social mediada pelo computador será uma interação mútua, pois os atores são afetados de forma conjunta.

Recuero (2009, p.68) acredita que as redes sociais são interdependentes umas das outras, ou seja, todas as pessoas podem estar ligadas umas às outras. Para a autora, rede social é sempre um conjunto de atores e suas relações:

[...] Trata-se das pessoas envolvidas na rede que se analisa. Os atores atuam de forma a moldar as estruturas sociais, através da interação e da constituição de laços sociais. Um ator, assim pode ser representado por um weblog, por um twitter ou mesmo por um perfil no facebook. E mesmo assim, essas ferramentas podem apresentar um único nó, como um weblog, por exemplo, que é mantido por vários atores (um grupo de autores no mesmo blog coletivo) RECUERO, 2009, p. 25.

Em resumo, a visão dessa autora destaca que as conexões feitas dentro de uma rede social são realizadas por laços sociais, ou seja, os indivíduos (atores) precisam ter algo em comum ou não, para haver algum tipo de interação social. Assim, os Sites de Redes Sociais, como Facebook e Twitter, são os espaços utilizados para a expressão das redes sociais na internet, sendo as curtidas e comentários no Facebook e as replys e retweets no Twitter forma de interação.

Sites de Redes Sociais foram definidos por Boyd \& Ellison (apud RECUERO, 2009, p.102) como aqueles sistemas que permitem 1) a construção de uma persona através de um perfil ou página pessoal; 2) a interação através de comentários; e 3) a exposição pública da rede social de cada ator. Os Sites de Redes Sociais permitem aos atores sociais maior conexão. Recuero (2009) explica que quanto mais conectado os atores, maiores as chances de receber determinados tipos de informação que estão circulando na rede. No caso de Sites de Redes Sociais, como o Twitter, quanto mais o indivíduo seguir um número 
determinado de perfis, mais conteúdo e informação ele terá.

Os atores citados por Recuero (2009) são identificados nos Sites de Redes Sociais por características singulares em seus perfis, imagens de exibição, gostos, paixões e ódios. Santos (2011, p.20) salienta que essa identificação pode ser feita por meio de representações gráficas ou imagens personalizadas chamadas de "Avatar", já que cada Rede Social disponibiliza um espaço na interface para que o usuário poste sua imagem. Como o autor explica, no caso das organizações, a imagem pessoal é substituída pelo logotipo da marca.

No Brasil, o uso de redes sociais na internet aumentou consideravelmente com o avanço da tecnologia (computadores, tablets e smartphones). Pesquisa de mídia realizada pelo IBOPE (2015), acessada em 22 de março de 2016, apontou que 42\% dos brasileiros utilizam a internet como meio de comunicação. Destes, 67\% utilizam para buscar informações e se entreter nos Sites de Redes Sociais. O Facebook está em primeiro lugar entre as redes sociais mais acessadas entre os entrevistados com 83\% de adesão, já o Twitter, popular entre os formadores de opinião, foi mencionado apenas por $5 \%$ dos entrevistados. Para Zago (2014, p.18), “esses números trazem indícios do papel proeminente das mídias sociais na internet no Brasil, e atestam a relevância de se estudar práticas sociais inseridas nesse cenário, como no caso da circulação jornalística através de redes sociais". Assim, pode-se dizer que as redes sociais na internet têm se destacado cada vez mais como um recurso para se obter informações e não apenas se entreter, principalmente o Twitter.

\section{Twitter}

O Twitter é um site popularmente conhecido como serviço de microbloging e pode ser encontrado no endereço: http://twitter.com. Ele foi criado em março de 2006 por Jack Dorsey, Biz Stone e Evan Willians em São Francisco, na Califórnia. Recuero (2009, p.173) explica que a ferramenta surgiu inicialmente como um projeto da empresa Odeo que apesar da estrutura semelhante aos blogs, iria possuir apropriações completamente diferentes. Essas apropriações defendidas pelos fundadores, diziam respeito à forma de escrever, comunicar e receber as mensagens dos outros usuários.

O site oficial do Twitter (2015) traz um breve resumo do que pode ser considerado a ferramenta: "é uma plataforma pública, aberta e conversacional que conecta pessoas instantaneamente com aquilo que é mais importante para elas. Nós geralmente dizemos que o Twitter é a distância mais próxima entre você e aquilo que mais ti interessa".

Zago (2014, p.42) observa que o Twitter pode ser considerado um Site de Rede Social na medida em que há perfis de identificação única reunindo as postagens de um determinado usuário. Conforme a autora, nele é possível seguir e ser seguido por outros usuários, ver quem segue quem, criar novos conteúdos (postar novos tweets, como são chamadas as atualizações nas ferramentas) e interagir com o conteúdo produzido por outros usuários em um fluxo de conteúdos (a timeline). As interações típicas permitidas pelo site incluem as atividades de menção através da “@” antes do nome do usuário.

A autora também observa que é possível reproduzir as mensagens compartilhadas por outros usuários pressionando o botão de retweet. Ainda, pode-se avaliar as mensagens ao pressionar o botão que permite marcar como favorito um determinado tweet ou enviar mensagens privadas por meio das 
direct messages. Em 2016, novas atualizações foram inseridas na ferramenta, como um botão para criar enquetes e postar gifs e uma nova forma de retweetar um tweet. Agora, o usuário pode ctiar o tweet de alguém escrevendo suas impressões em cima. Além disso, a funcionalidade moments agrupa todos os acontecimentos mais comentados do dia em pequenos textos divididos em categorias: hoje, entretenimento, esporte, notícias e diversão.

Em outra pesquisa também realizada em 2014, a autora Zago ressalta que cada mensagem publicada na ferramenta, ou tweet, deve ter no máximo 140 caracteres. Além disso, o Twitter inclui recursos específicos como RTs, @ replies e \#hashtags, e requer uma alfabetização própria. Ou seja, para utilizar a ferramenta, é necessário conhecimento da linguagem utilizada. Se os indivíduos (atores) não entenderem essa linguagem num primeiro contato, se sentirão perdidos. Abaixo um exemplo dos mecanismos do Twitter:
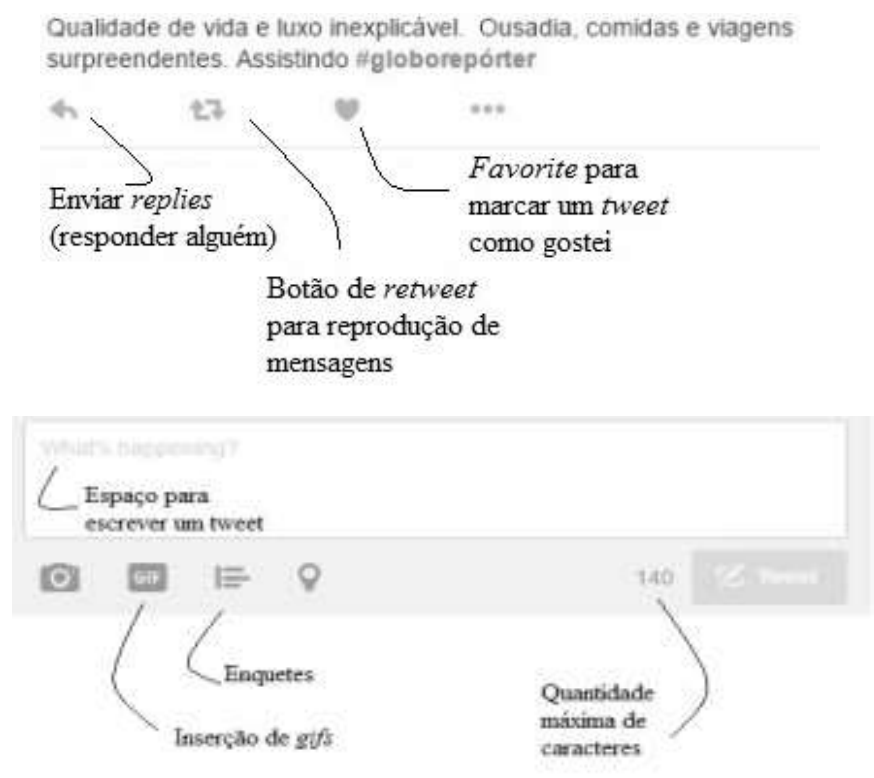

Os autores Santaella e Lemos (2010, p.73) explicam que "Ao escolher quais microblogs iremos seguir, estamos escolhendo quais canais de informação iremos convidar para fazer parte de nosso fluxo de informações. Quando seguimos alguém no Twitter, está fazendo-se uma 'assinatura' do seu canal de informações".

No Twitter, o usuário também pode usar um RT (retweet) em forma de resposta mencionando diversos@ @usuários e \#hashtags. Thiel (2012) explica em seu site: "A hashtag do Twitter é simplesmente uma frase-chave, por extenso, sem espaços, com um sinal de sustenido (\#) na frente". A autora ainda afirma: "a hashtag do Twitter une as conversas de usuários diferentes em uma linha única, que você pode encontrar pesquisando a hashtag na busca do Twitter". Dessa forma, durante exibição de alguns programas, uma hashtag é lançada para que o público comente sobre aquele assunto. Lemos e Santaella (2010, p. 109) explicam que ocorre num único tweet, a penetração simultânea em múltiplos fluxos individuais e/ou coletivos em tempo real, caracterizando a interatividade pluridirecionada dessa micromídia móvel. Assim, observa-se que em apenas uma única mensagem o usuário é capaz de utilizar diversas funções do site.

O Twitter foi palco de grandes repercussões como a Primavera Árabe, os protestos de junho de 2013 no Brasil e a Copa do Mundo de 2014 ainda no Brasil. Segundo uma pesquisa realizada pelo microblog e divulgada pelo @TwitterAdsBr (2015), apesar da relevância, o Twitter fechou o ano de 2015 com 320 milhões de usuários. Desse total, $80 \%$ são usuários mobiles (acessam a rede social por meio de tablets e smartphones), 58\% são homens contra $42 \%$ das mulheres. Além disso, o maior número de usuários da ferramenta tem entre 25 e 44 anos (22\%) e 21 e 24 anos (21\%). Outro dado importante dessa pesquisa é a relação dos twitteiros com a televisão: 98\% assiste TV todos os dias, enquanto um em cada 
quatro usuários procura por informação sobre o que assiste e um em cada cinco divide sua opinião sobre os programas de TV.

Em entrevista à Redação Adnews, Guilherme Ribenboim (2015), vice-presidente do Twitter na América Latina, afirma que a estratégia de crescimento para 2016 está baseada em três pilares principais: vídeos digitais, integrações com programas de TV e parcerias comerciais com empresas aproveitando grandes eventos como carnaval, olimpíadas e eleições. Além disso, a empresa pretende trabalhar para expandir as integrações que realiza com programas de TV no país em diferentes segmentos, como os reality shows, telejornais, programas esportivos e novelas. Os formatos tradicionais como a televisão vêm mostrando seu potencial na plataforma. A prova disso é o enorme sucesso que Masterchef, exibido pela Band, teve na rede social durante o ano de 2015, e o The Voice Kids teve durante os domingos exibido pela Rede Globo, observa o vice-presidente:

Por ser uma plataforma aberta, sem filtro e de
conversa em tempo real, o Twitter tem o
potencial de viralizar um conteúdo
rapidamente, o que é muito importante para o
contato entre as marcas e o público. E os
programas de TV têm percebido cada vez
mais que a interação com o público tem
efeitos extremamente positivos sobre a
audiência (RIBENBOIM, 2015).

Os programas de TV acabaram se adequando a essa ferramenta. No perfil do Twitter Globo Repórter, objeto desse estudo, por exemplo, há 520 mil seguidores. O programa não utiliza as ferramentas para comunicar-se com o público diretamente respondendo mensagens ou reproduzindo. A forma mais próxima de abordar o telespectador, são com as postagens durante a semana feitas com vídeos dos repórteres convidando para assistir ao programa, gifs (imagens de poucos segundos que se mexem) e imagens dos lugares onde as reportagens foram realizadas, além de links para assistir aos programas anteriores. É durante a exibição que o uso da hashtag \#GloboReporter é disponibilizado pelo perfil oficial e as interações com retweets, replys e favorites dos usuários acontecem com mais frequência. Veja a seguir um exemplo de interação do Twitter do Globo Repórter chamando o telespectador para assistir ao programa:

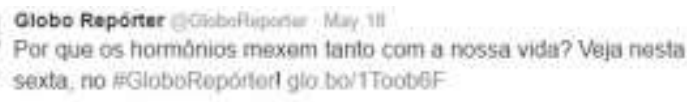

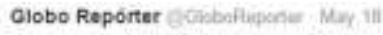
Por que os hormónios mexem fanto com a nossa vidu? Veja nesta sexta, no FGloboRoported glo bor TToob6F

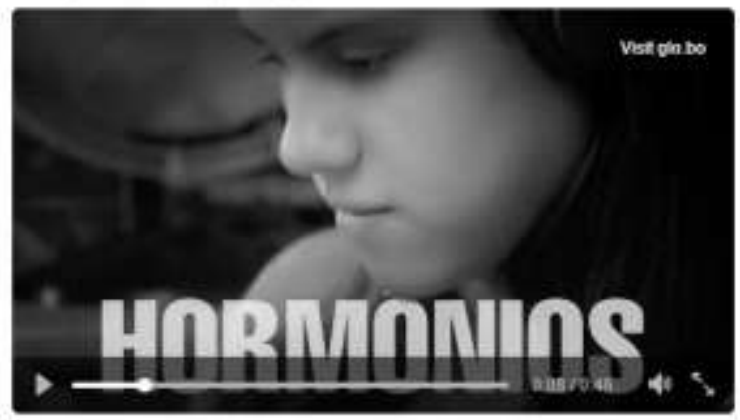

\section{METODOLOGIA}

Para a realização dessa pesquisa foram coletados 275 comentários sobre a edição de Abu Dhabi no dia 29 de abril de 2016 das 22 h17 às 23 h17. Como os dois programas seguintes não tiveram uma boa repercussão e ouve coincidência de temas, analisou-se um terceiro programa no dia 20 de maio de 2016 das 22 h16 às 23 h16 sobre a edição Hormônios com o total de 45 comentários. Esses comentários foram coletados através do uso da hashtag do programa: \#globoreporter por meio de prints da timeline. Depois foi feito um recorte para selecionar os tweets e classificá-los em categorias, já que as pessoas comentam sobre diferentes assuntos dentro de uma mesma edição. Classificou-se também em gêneros e de forma qualitativa obtendo elogios e críticas. Abaixo está um exemplo de como as 
categorias foram organizadas em cores para a realização da pesquisa:

\begin{tabular}{|c|c|c|c|}
\hline Gênero & Elogio/Crítica & Programa/viagem/ povo & Tweet \\
\hline Mulher & Elogio & Programa & Me maravilhar com as riquezas alheias no Globo \\
Repórter.
\end{tabular}

O fato de classificar os comentários facilitou a conexão das falas e ajudou na hora da construção de um discurso, pois utilizou-se a técnica do Discurso do Sujeito Coletivo (DSC) proposto por Lefévre\&Lefévre (2003), em que a soma de discursos singulares produz um discurso coletivo:

(...) uma modalidade de apresentação de resultados de pesquisas qualitativas que tem depoimentos ou outros tipos de texto como matéria-prima, sob a forma de um ou vários tipos de discursos-síntese escritos na primeira pessoa do singular, expediente que visa expressar o pensamento de uma coletividade, como se essa coletividade fosse o emissor de um discurso (LEFÉVRE E LEFÉVRE, 2003, p. 35).

Segundo Lefévre\&Crestana\& Cornetta (2003,

p.70) o Discurso do Sujeito Coletivo é uma modalidade de apresentação de resultados de pesquisas qualitativas, que tem depoimentos como matéria prima, sob a forma de um ou vários discursossíntese escritos na primeira pessoa do singular. Sendo assim, expressa o pensamento coletivo tornando-o emissor de um discurso:

Esta técnica consiste em selecionar, de cada resposta individual a uma questão, as Expressões-Chave, que são trechos mais significativos destas respostas. A essas Expressões Chaves correspondem Ideias
Centrais que são a síntese do conteúdo discursivo manifestado nas Expressões Chave. Com o material das Expressões Chave das Idéias Centrais constroem-se discursossíntese, na primeira pessoa do singular, que são os DSCs, onde o pensamento de um grupo ou coletividade aparece como se fosse um discurso individual (LEFÉVRE, CRESTANA E CORNETTA, 2003, p.70).

As Expressões-Chave (ECH) são definidas por Figueiredo\&Chiari\&Goulart (2013, p.132) como pedaços e trechos do discurso que revelam a essência do conteúdo. Já as Ideias Centrais (IC) são defendidas por esses autores como o nome ou expressão lingüística que revela, descreve e nomeia, da maneira mais sintética e precisa possível, o sentido presente em cada uma das respostas analisadas e de cada conjunto homogêneo de expressões-chave, se tornando posteriormente o Discurso do Sujeito Coletivo.

A técnica desenvolvida por Lefévre\&Lefévre (2003) foi aplicada aos comentários do Twitter durante a exibição de dois programa do Globo Repórter. De cada tweet tirou-se ideias centrais a fim de formar o discurso coletivo dos telespectadores do programa. Assim, nesta pesquisa, o discurso singular proposto por um único telespectador/internauta foi 
agrupado com outros discursos formando um discurso coletivo.

\section{LEVANTAMENTO DE DADOS: Primeira leitura}

Nesta primeira leitura, o programa analisado no dia 29 de abril das $22 \mathrm{~h} 17$ às $23 \mathrm{~h} 17$ abordou como é a vida em Abu Dhabi. Uma leitura geral dos tweets foi realizada identificando as possíveis categorias para classificá-las. Ficou categorizado da seguinte forma: Programa (relatos sobre o Globo Repórter naquele dia, atuação dos repórteres); Tema (viagem, relacionado ao lugar visitado e cultura) e Povo (sobre a população brasileira, governo e país). Os comentários foram divididos entre elogios e críticas. Sendo 54,76\% elogios e 45,23\% críticas. A pesquisa também identificou que 53,09\% dos comentários partiram dos homens, enquanto $46,90 \%$ eram das mulheres, o que mostra um certo equilíbrio no quesito gênero.

No segundo Globo Repórter analisado no dia 20 de maio das 22 h16 às $23 \mathrm{~h} 16$, o tema central foi a função dos hormônios no corpo humano. Usou-se a mesma técnica dividindo os tweets em três categorias: Programa (sobre o Globo Repórter e atuação dos repórteres); Tema (hormônios) e Povo (população brasileira e país). Separando-os em elogios e críticas. Definiu-se que $54,76 \%$ dos comentários eram elogios e $45,23 \%$ eram críticas. Dentre esses, $54,54 \%$ eram mulheres, enquanto $45,45 \%$ foram feitos por homens. Assim, fez-se uma lista de todos os tweets enviados sobre cada um dos programas.

\section{Segunda leitura}

$\mathrm{Na}$ segunda leitura foram selecionados os tweets mais significativos dos telespectadores para que pudéssemos retirar suas expressões-chaves (ideia central), ou seja, aqueles que traziam sentido e clareza dentro de todas as categorias e assim formar um discurso coletivo. Os tweets possuem no máximo 140 caracteres, alguns deles, nem chegam a este número. Mas, mesmo assim, foi possível extrair uma ideia central de cada tweet selecionado. Vejamos a seguir exemplos de tweets com poucos caracteres:



\section{\#GloboReporter mais fütil que já assisti}

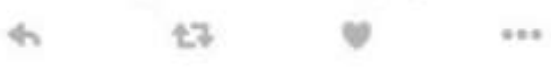

"GloboReporter é bem pra mim hoje

\section{Uma dica: o \#GioboReporter tá com tema ótimo meninas}

Agora, abaixo a seleção das ideias centrais dos comentários dentro de cada categoria e, em seguida, o discurso coletivo de cada tweet selecionado.

Sendo $\mathrm{T}=$ Telespectadores;

\section{GLOBO REPÓRTER - ABU DHABI}

\section{PROGRAMA}

T1: Maravilhar com riquezas alheias; (Mulher; Elogio)

T2: Aventura mágica; (Mulher; Elogio)

T3: Tá incrível; (Homem; Elogio) 
T4: "Adoroo". (Mulher; Elogio)

T5: Viagens surpreendentes. (Homem; Elogio)

T6: Super interessante. (Homem; Elogio)

T7: Fútil. (Mulher; Crítica)

T8: Repórter fraca. (Mulher; Crítica)

T9: Estou sem palavras. (Homem; Elogio)

T10: Que bosta! (Homem; Crítica)

\section{TEMA}

T1: Quero morar em Abu Dhabi; (Homem; Elogio)

T2: Não tenho dinheiro pra nada; (Homem; Crítica)

T3: Quanta coisa linda de se ver; (Mulher; Elogio)

T4: Fascinada com Abu Dhabi; (Mulher; Elogio)

T5: Ditadura da beleza; (Mulher; Crítica)

T6: Apaixonada por Abu Dhabi; (Mulher; Elogio)

T7: Pra quê ficar comendo ouro? (Homem; Crítica)

T8: Vivem como se não existisse grupos terroristas;

(Mulher;Elogio)

T9: Quanta fortuna! (Homem/Elogio)

T10: Dinheiro gasto com inutilidades.

(Homem;Crítica)

\section{POVO}

T1: Se essa mesquita fosse aqui no Brasil já estaria toda pichada; (Mulher; Crítica)

T2: Capuccino é caro; (Mulher; Crítica)

T3: Lanches com pó de ouro; (Mulher; Crítica)

T4: Não investe em energias renováveis; (Homem; Crítica)

T5: No Brasil não teria tanta desigualdade, corrupção e violência; (Homem; Crítica)

T6: No Brasil é tudo muito desorganizado; (Homem; Crítica)

T7: Come ouro; (Mulher; Crítica)

T8: Ótimo se os pacientes do Brasil fossem tratados como as aves; (Homem; Crítica)

T9: Certos eles em querer ficar em Abu Dhabi; (Mulher; Crítica)

T10: As mulheres têm segurança em sair à noite. (Mulher; Crítica)

DISCURSO COLETIVO SOBRE O GLOBO REPÓRTER - ABU DHABI

\section{PROGRAMA}

É uma incrível aventura mágica com viagens surpreendentes em que pode se maravilhar com as riquezas alheias. Adoro, estou sem palavras. Por outro lado é fútil, a repórter é fraca, que bosta;

\section{TEMA}

Quanta coisa linda de se ver, quanta fortuna, fascinada e apaixonada por Abu Dhabi, um lugar sem terrorismo, quero morar lá. Pra quê comer ouro? Não tenho dinheiro para nada, dinheiro gasto com inutilidades e ditadura da beleza;

\section{POVO}


Lá a mulher tem segurança, lanche com pó de ouro, ótimo se os pacientes do Brasil fossem tratados como as aves, aqui é tudo muito desorganizado, tem desigualdade, corrupção e violência, capuccino caro, não investe em energias renováveis, a mesquita no Brasil já estaria pichada, certos eles em querer ficar em Abu Dhabi;

\section{GLOBO REPÓRTER - HORMÔNIOS}

\section{PROGRAMA}

T1: Bem pra mim; (Mulher; Elogio)

T2: Tema ótimo meninas. (Mulher; Elogio)

T3: Quando? Onde? (Homem; Elogio)

T4: Melhor programa; (Homem; Elogio)

T5: Podre é essa emissora; (Mulher; Crítica)

T6: Irado; (Homem; Elogio)

T7: Prefiro quando fala da cultura de outros países; (Homem; Crítica)

T8: É sexta à noite e eu em casa assistindo. (Homem; Elogio)

\section{TEMA}

T1: Quem é o sexo frágil agora?(Mulher; Elogio)

T2: A gente fica louca; (Mulher; Elogio)

T3: Hormônios a flor da pele; (Mulher; Crítica)

T4: Menopausa está traumatizando; (Mulher; Crítica)

T5: Tenta conseguir corpo musculoso e saudável; (Homem; Crítica)
T6: Alimentação saudável, atividade física; (Homem; Crítica)

T7: A cara da adolescente; (Mulher; Crítica)

T8: Se deu mal usando testosterona. (Homem; Crítica)

\section{POVO}

T1: Alô marombeiros; (Homem;Elogio)

T2: A classe média com menopausa usando ar condicionado 17 sofre, né? (Mulher; Crítica)

T3: Gente pobre, coitadinhos. (Mulher; Crítica)

\section{DISCURSO COLETIVO SOBRE O GLOBO REPÓRTER - HORMÔNIOS}

\section{PROGRAMA}

Quando? Onde? É sexta à noite e eu assistindo, 65 melhor programa, tema ótimo, irado, é bem pra mim, mas prefiro quando fala da cultura de outros países, podre é essa emissora;

\section{TEMA}

A gente fica louca, hormônios a flor da pele, tenta conseguir corpo musculoso com alimentação saudável e atividade física, quem é o sexo frágil? A cara da adolescente, menopausa está traumatizando, se deu mal usando testosterona;

\section{POVO}

Alô marombeiros, a classe média na menopausa com ar condicionado sofre, né? Pobres, coitadinhos; 


\section{Análise do Discurso do Sujeito Coletivo: a opinião do telespectador do Globo Repórter}

O desenvolvimento do discurso do sujeito coletivo baseado nos comentários do telespectador do Globo Repórter revela um telespectador atento aos detalhes do programa e a forma como as reportagens são retratadas na televisão. Na primeira categoria PROGRAMA sobre Abu Dhabi foi fácil perceber o quanto o telespectador se identifica com o que é passado para ele. Dentre os dez comentários selecionados para análise, sete eram elogios. Isso mostra a satisfação do telespectador em assistir o Globo Repórter. Eles querem se maravilhar com as riquezas alheias e viagens surpreendentes, adoram e acham o programa incrível, mas ao mesmo tempo o definem como fútil por mostrar apenas a riqueza de Abu Dhabi.

No discurso observou-se também, a atuação do repórter, como lembra Rezende (2007, p.12), "na década de 80, o programa precisou contratar os repórteres do telejornalismo da própria emissora para que pudesse suprir a demanda das grandes reportagens". Mas, nem todo mundo se contenta com o trabalho realizado por eles. No discurso deste programa, os telespectadores acharam a atuação da repórter fraca.

Já na categoria sobre o TEMA do Globo Repórter Abu Dhabi, percebeu-se como o telespectador se interessa pela cultura de outros países. A maioria dos comentários retratavam a fascinação por conhecer um lugar diferente. Esse discurso recorda o que Souza (2004, p.145) afirmou sobre a época em que o Globo Repórter tinha formato de documentário: levava a "realidade de outros países e outras culturas". Assim, os telespectadores ficaram apaixonados e fascinados pela riqueza e quantidade de coisas lindas para se ver, além do lugar não conter violência. Por outro lado se indignaram pela forma como o ouro é utilizado nas comidas e na ditadura da beleza sofrida pelas camelas.

$\mathrm{Na}$ categoria POVO notou-se uma comparação entre Abu Dhabi e o Brasil, não somente nas questões relacionadas à cultura, mas principalmente sobre a gastronomia, políticas públicas e infraestrutura. Os telespectadores relatam que lá as mulheres têm segurança e os animais são tratados em ótimos hospitais, bem diferente do que acontece no nosso país. Além disso, as comidas são feitas com ouro e equivalem ao mesmo valor das comidas normais vendidas por aqui. Por isso, na perspectiva dos telespectadores, é aceitável que pessoas queiram mudar-se para Abu Dhabi em busca de melhores condições de vida.

No segundo Globo Repórter analisado, o discurso dos telespectadores sobre a primeira categoria PROGRAMA, retrata a abordagem que a emissora dá para o tema hormônios. Eles acham que o Globo Repórter é irado e o melhor programa por tratar de um assunto ótimo em que eles se identificam. Inclusive, não reclamam por ficar sexta-feira em casa assistindo ao programa. De outra maneira, ressaltam que há um interesse maior quando o programa fala da cultura de outros países. Talvez seja por esse gosto dos telespectadores sobre coisas novas, que Priolli (1985, p. 33) afirma que o programa teve "uma participação de 70\%" do público, ou seja, uma grande audiência desde sua estreia.

Sobre o TEMA deste programa, foi notória a presença das mulheres comentando o assunto. $\mathrm{O}$ discurso mostrou que elas ficam loucas, com os 
hormônios a flor da pele e se perguntam: quem é o sexo frágil? Além disso, os telespectadores explicam que para conseguir um corpo musculoso, é preciso ter alimentação saudável e praticar atividade física. Por outro lado, se traumatizam com a menopausa e criticam o uso indevido da testosterona.

Por fim, a categoria POVO do Globo Repórter sobre hormônios, revela que as pessoas fizeram pouca conexão do tema com a população e as políticas públicas. Enquanto as outras duas categorias tiveram oito comentários selecionados, esta teve apenas três. O discurso coletivo ironizou os marombeiros - aqueles que se dedicam a criar músculos tomando hormônios , a classe média com menopausa utilizando ar condicionado no 17, enquanto classes inferiores são obrigadas a lidar com o calor, e os definiu como pobres e coitadinhos.

\section{CONCLUSÃO}

Após a análise sobre os discursos dos telespectadores, acredito que a pergunta inicial sobre o que o telespectador do Globo Repórter comenta no Twitter durante a exibição do programa tenha sido respondida. Notou-se que os telespectadores se preocupam muito com a forma que os assuntos são retratados no programa. Desde o tema, formato, abordagens e atuação dos repórteres. Outra preocupação dos telespectadores é relacionar o que é dito no programa com o seu cotidiano.

No Globo Repórter sobre Abu Dhabi, percebeu-se a fascinação e o entusiasmo do telespectador perante as novas descobertas e culturas mostradas na televisão. Muitos deles nunca saíram do país e o programa tem esse poder de "transportar" a pessoa que está assistindo até outros lugares do mundo. Quem está em casa, além de se apaixonar por novos lugares, é capaz de conhecer a cultura de outros países, que jamais pensou em visitar, tudo isso, enquanto assiste ao programa.

Além disso, relacionar a cultura de outro povo com a cultura a qual estamos acostumados, não é tarefa fácil. $\mathrm{O}$ telespectador se indigna pela quantidade de ouro existente em Abu Dhabi e a forma como eles o consomem. Afinal, enquanto lá, eles comem ouro, em lugares pobres do Brasil, mal se tem o que comer.

Já no Globo Repórter sobre o efeito dos hormônios no corpo, percebeu-se um telespectador preocupado com a sua saúde e seu bem estar. $\mathrm{Na}$ maioria dos comentários, as mulheres foram as que mais comentaram sobre o tema do programa. Isso mostra o quanto elas se interessam em se cuidar e saber como determinados hormônios agem dentro do corpo humano.

Em contrapartida, observou-se por parte dos telespectadores, um julgamento pelas fontes escolhidas para as reportagens. Enquanto o programa mostrava mulheres de classe média sofrendo com os sintomas da menopausa, como o calor, no Twitter, os telespectadores ficavam indignados pela forma que a personagem lidava com isso, através do uso do ar condicionado na temperatura 17. Grande parte da população não pode comprar este equipamento, por isso a ironia "pobres e coitadinhos".

Ao final desta pesquisa, concluiu-se que o Globo Repórter possui um equilíbrio quanto ao gênero de quem assiste ao programa e comenta no Twitter ao mesmo tempo. $\mathrm{O}$ estudo mostrou que no primeiro programa analisado 53,09\% dos comentários partiram dos homens, enquanto $46,90 \%$ foram das mulheres, já no segundo programa sobre hormônios manteve-se o 
mesmo equilíbrio com $54,54 \%$ de comentários das mulheres, enquanto 45,45\% eram dos homens. Além disso, a pesquisa constatou que os telespectadores do programa fazem mais elogios do que críticas, mas os percentuais se igualam nos dois programa, sendo $54,76 \%$ elogios e $45,23 \%$ crítica. Notou-se também, que, em maior quantidade, o telespectador costuma relacionar os assuntos retratados no programa com as diferentes questões do seu dia-a-dia, ou seja, é comum que ele faça relação com a sua realidade.

\section{REFERÊNCIAS}

ADNEWS (São Paulo); RIBENBOIM, G. 40,5 milhões de usuários são impactados por ações no Twitter. 2015. Disponível em: < http://www.adnews.com.br/internet/mais-de-40milhoes-de-usuarios-brasileiros-sao-impactados-poracoes-no-twitter > Acesso em: 21 de março de 2016.

ANDRADE, João Batista. O Povo Fala: um cineasta na área de jornalismo da TV Brasileira. São Paulo: Senac, 2002.

BASTOS, Marco Toledo; ZAGO, Gabriela da Silva. Visibilidade de Notícias no Twitter e Facebook: análise comparativa das notícias mais repercutidas na europa e nas américas. Artigo publicado pela SBPjor, 2013.

CLICKRBS (Porto Alegre). Twitter completa 10 anos com prestígio de ferramenta social. 2016. Disponível em: < http://zh.clicrbs.com.br/rs/vida-eestilo/noticia/2016/03/twitter-completa-10-anos-comprestigio-de-ferramenta-social-4991335.html Acesso em: 21 de março de 2016

COSTA, Maria Hughes Guerreiro. O modo de Endereçamento do Globo Repórter. Grupo de Análise de Telejornalismo: UFBA, 2009.

FIGUEIREDO, M.Z.A; CHIARI, M.B; GOULART, B.N.G. Discurso do Sujeito Coletivo: uma breve introdução à ferramenta de pesquisa qualiquantitativa. Distúrb Comun, São Paulo, 25(1): 129-136, abril, 2013

IBOPE (Brasil, Presidência da República. Secretaria de Comunicação Social). Pesquisa brasileira de mídia 2015 : hábitos de consumo de mídia pela população brasileira. - Brasília : Secom, 2014.

LINS, Consuelo. O Documentário de Educação Coutinho: televisão, cinema e vídeo. Rio de Janeiro: Jorge Zahar Editor, 2004.

LEFÉVRE, F.; LEFÉVRE, A.M.C. O sujeito coletivo que fala. Interface - Comunic, Saúde, Educ, v.10, n.20, p. 517-24, jul/dez. 2006.

LEFÉVRE, A.M.C; CRESTANA, M.F; CORNETTA, V.K. A utilização da metododologia do discurso do sujeito coletivo na avaliação qualitativa dos cursos de especialização "Capacitação e Desenvolvimento de Recursos Humanos em Saúde-CADRHU, São Paulo - 2002. Revista Saúde e Sociedade v.12, n.2, p.68-75, jul-dez 2003

MELO, Geraldo Anhaia. Muito Além do Cidadão Kane. $1^{\circ}$ edição: São Paulo, 1994.

PRIMO, Alex. Interação Mútua e Reativa: uma proposta de estudo. Revista da Famecos, n. 12, p. 8192, jun. 2000.

PRIOLLI, Gabriel. A tela pequena no Brasil grande: anos 50: o patrocinador faz o show. Rio de Janeiro: Jorge Zahar Editor, 1985.

RECUERO, Raquel. Redes Sociais na Internet. Porto Alegre: Sulina, 2009. 
